\title{
Detection of bone preservation in archaeological and fossil samples
}

\author{
Margaret J. Schoeninger* \\ Department of Anthropology, Peabody Museum, Harvard University, Cambridge, MA 02138, U.S.A.
}

KATHERINE M. MOORE

Department of Anthropology, University of Michigan. Ann Arbor, MI 48109, U.S.A.

Matthew L. Murray and John D. Kingston

Department of Anthropology, Peabody Museum, Harvard University, Cambridge, MA 02138, U.S.A.

\begin{abstract}
Several methods for assessing the preservation of the organic and inorganic components of bone are discussed. Aspects of bone composition (i.e. specific trace element concentrations and stable isotope ratios) provide information on diet and health status in prehistoric and fossil humans. Such information is valuable in understanding the evolution of human adaptation but, prior to the analysis of bone. it is necessary to ensure that the biological signature has not been erased during burial or following excavation. The purpose of the present study was to provide relatively quick methods of scanning sets of bones in order to eliminate ones that are not appropriate for analysis. We present the results of powder $\mathrm{X}$-ray diffractometry and a survey of thin sections of human bones recovered from a coastal site in Georgia (U.S.A.) to assess the preservation of biogenic bone mineral and histological structure. Those bone samples which displayed a lack of histological structure also showed X-ray diffraction patterns which deviated markedly from that of fresh bone. We conclude that a survey of thin sections of a small number of samples in any skeletal population is a rapid, dependable means of eliminating bone which has been altered diagenetically. We also present the results of amino acid analysis of "gelatin" collected using two different methods of extracting the organic component in bone. The "gelatin" which resulted from the demineralization of bone pieces in weak acid $(1 \% \mathrm{HCl})$ consistently showed a pattern of amino acid composition similar to collagen. Conversely, the "gelatin" which resulted by hydrolyzing demineralized bone powder was unreliable in the retention of protein. Thus, use of the former method, rather than $\mathrm{C}$ to $\mathrm{N}$ ratios or \% yield, appears to be the best means of ensuring analysis of material retaining a biological signature. At this point in time, we can identify bone samples appropriate for trace element and stable isotope analysis even though we cannot always identify the diagenetic process or agent involved.
\end{abstract}

\section{INTRODUCTION}

A MAJOR problem confronting analysts of archaeological or fossil bone is the assessment of its biological integrity. As discussed most recently by HANSON and Buikstra (1987), it is difficult to determine the preservation of the organic or inorganic fraction of bone based on external morphology. The burial and fossilizing environments present such a variety of conditions (STout, 1978) that, as yet, no predictable patterns of interaction among environment, external morphology and internal preservation have been detailed (see PATE, 1989, for a promising approach to the problem).

This difficulty is especially critical to anthropologists attempting to reconstruct an individual's diet or health status from the chemical or isotopic composition of the skeleton. Bone is obtained from diverse sources and has been subjected to a variety of experiences (see Fig. 1). For example, in our labora-

* Present address: Department of Anthropology, University of Wisconsin, Madison, Wisconsin 53706. U.S.A. tory we have modern samples collected from the land surface in the harsh, desert environment of northern Kenya as well as museum specimens (one collection from Yugoslavia will be discussed later in this paper) which have had variable, often unknown, treatment following excavation and during storage. Also, given the wide research interests of the personnel in the laboratory (biological anthropology, European prehistory, faunal analysis, human paleontology) we are analyzing recently excavated material from regions as diverse as highland Peru, Alaska, New Mexico, Nevada, coastal Georgia, central Europe, Egypt and Syria. These collections represent different cultural periods including the Middle Paleolithic, early Neolithic, Iron Age, Woodland, Mississippian and Protohistoric and date from $50 \mathrm{ka} \mathrm{B}$.P. to $1800 \mathrm{~A}$.D. This diversity results from concern with problems, such as the introduction of agriculture, the development of animal husbandry, the evolution of social systems, and the appearance of Homo sapiens. All of these require consideration of multiple archaeological or paleontological sequences from across the globe.

The samples which we analyze are limited by availability. Thus, the skeletal sample comes as part of the 


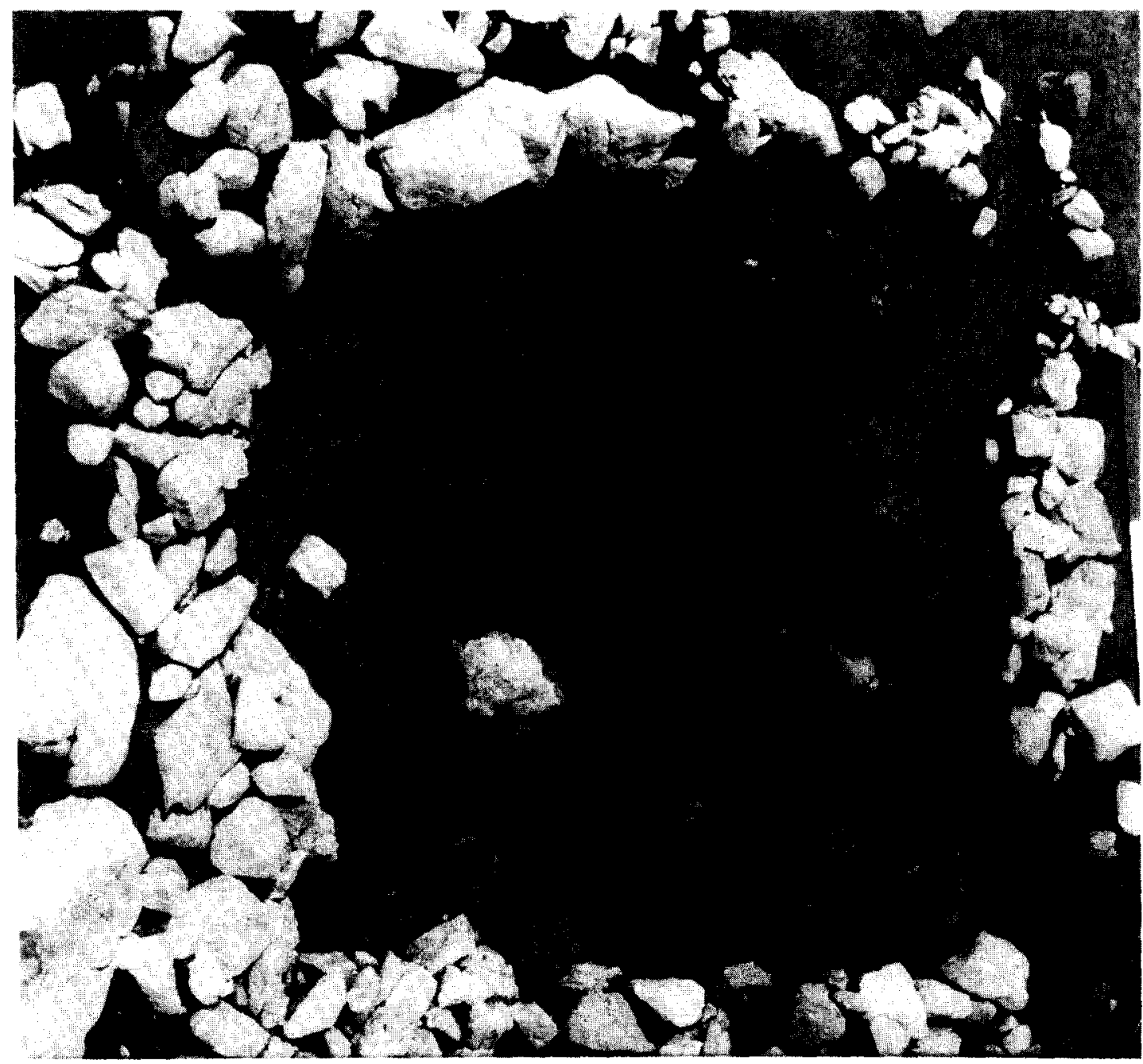

FIG. 1. Typical depositional environment of archaeological bone specimens (Iron Age, Europe). Each sample must be screened before chemical or isotopic analysis.

problem. Because of limited availability, there has been the temptation to do chemical or isotopic analyses on all bone irrespective of the appropriateness of the sample in terms of preservation. When the results of the analysis match expectation, there has been the inclination to accept them as meaningful. Otherwise, the results are rejected from consideration. Put in these terms, a circularity is obvious.

Over the past several years, we have sought methods that are independent of our archaeometric analyses to direct our choice of bone samples for analysis. In this paper we present several checks at different stages of sample preparation through which preservation can be assessed. Some of these checks deal primarily with retention of the mineral fraction in order to determine the feasibility of trace element analysis. Others are used to assess the possibility of obtaining biologically determined signals from isotopic ratios of $\mathrm{C}$ and $\mathrm{N}$ in organic residues recovered from bone.

\section{THE INORGANIC FRACTION OF BONE}

\section{The problem}

Studies (summarized in PrICE et al., 1985) have indicated that the concentrations of certain trace elements in fresh bone (most commonly, $\mathrm{Sr}$ ) reflect the concentrations of those elements in diet. Even so, analyses of archaeological samples have demonstrated that massive chemical alteration, obliterating the original chemical signal, can take place in bone (LAMBERT et al., 1984; GrUPE, 1988, 1989; GrupE and Herrmann, 1988; Grupe and Piepenbrink, 1989). Commonly, fauna of known diets (e.g. carnivores and herbivores) from the same burial environment as the humans are analyzed. If the fauna display the expected pattern of trace elements, then the human samples are presumed to retain biologically intact bone mineral. Obviously, problems arise when no fauna exist, such as in many museum collections. 
Further, this is not a conclusive check on preservation of the sample of interest. Another approach has been the use of X-ray diffractometry on unashed, powdered bone samples to check for alteration in the crystallinity of bone mineral (following the work of Posner, 1969; Schoeninger, 1979; Shipman et al., 1984). All buried bone analyzed thus far using this technique appears to be altered to some extent. For this reason, it is difficult to decide which bones should be eliminated from chemical analysis. Others have suggested studying thin sections to assess retention of histological structure (Stout, 1978). Some completely fossilized bone, however, retains structure at this level while, presumably, having undergone chemical alteration (WALKER et al., 1982).

It was proposed that if a pattern between histological structure and X-ray diffraction profiles was observed, it could serve as a check for preservation. In order to test this proposition, human bones from an archaeological site dating to the 16th century A.D. on the Georgia coast of North America (see SCHOENINGER et al.. 1989) and a modern control were prepared as outlined below.

\section{Thin section preparation}

Thin sections were prepared for nine human samples, eight archaeological and one modern control (cadaver specimen). In all cases except two, slides were made from transverse sections of the tibia, typically from the middle portion of the diaphysis. Thin sections of two samples, 2032 and 3714 (the modern control), were made from cross-sections of ribs. The more intact samples were cut using a large clectric diamond saw while the more friable samples (e.g. ribs) were cut with a jeweler's saw. Samples were embedded in epoxy and allowed to cure overnight. They were then lapped down on one side and epoxied to glass slides. Samples were sectioned to approximate thickness with a slow-speed Isomet petrographic saw. The sections were then ground down to desired thickness using a glass lap plate and No. 600 grit.

\section{$X$-ray diffraction}

The same samples were prepared for X-ray diffraction analysis. Powder slides were prepared by grinding bone powder (previously ground at liquid $\mathrm{N}$ temperature in a SPEX mill to $<0.71 \mathrm{~mm}$ ) in an agate mortar using acetone to make a slurry. When the sample was ground to a uniform texture, with particles fine enough to remain momentarily in suspension in the acetone, the mixture was poured quickly onto a glass slide to avoid any settling into some preferred orientation by the particles. The slide was tilted back and forth during the time of evaporation of the acetone. This method produced a smooth, even coating of powder on the slide.
It was difficult to prepare acceptable powder slides for the modern sample used as a control. Collagen, a tough fibrous material, prevents breakdown of bone in an agate mortar to sizes small enough to avoid settling of particles in preferred orientation on the slide. Such preferred orientation interferes with the $\mathrm{X}$-ray diffraction patterns. Replacing the bone in the SPEX mill at liquid $\mathrm{N}$ temperature for an additional $4 \mathrm{~min}$ reduced the size fraction to one manageable in the agate mortar. No difference in patterns was observed between this preparation and additional aliquots of bone powder from the same sample ground for longer periods of time in the Spex mill. For this reason we can assume that the profiles presented below do not reflect preferred orientation of the powder on the slides.

\section{Results}

In thin section, all of the samples displayed extensive alteration (similar to that seen in Fig. $2 \mathrm{c}$ and d) when compared with well preserved bone (Fig. $2 \mathrm{a}$ and $b$ ). Intact Haversion systems were observed in all sections to a limited and variable extent, although there was no apparent pattern of distribution of these relatively unaltered areas (e.g. adjacent to periosteum vs endosteum). This suggests that, at least in this set of bone samples, diagenesis was not a process that moved through the bone in a simple manner from the surface inward. It appears that the Haversian canals and interstitial spaces have provided longitudinal pathways in the bone, creating complex alteration patterns.

The above interpretation of bone alteration is further supported by a comparison of the thin section data with the X-ray diffraction data from each sample. A semi-quantitative assessment was made of the portion of the surface of the thin-section retaining intact histological structure. The nine thin sections were studied by two individuals and ranked according to the estimated percent retention of histological structure. The two individuals gave virtually identical rankings and their combined results are presented in Table 1. There is a range of preservation from those with the least amount of observable structure (labelled "trace") to some samples in which as much as $30 \%$ of the cross section retained structure.

The X-ray diffraction data produced a pattern which correlated with that of the thin sections. There is a clear distinction between the modern and archaeological samples and also between the archaeological material with well preserved histological structure and that with poorly preserved structure. The modern samples produced profiles of diffuse blunted peaks with poor definition, especially in the $32^{\circ} 2 \theta$ area where four large peaks overlap (see Fig. 3). At the other extreme, the bone with the least well preserved histological structure yielded patterns with much sharper, more distinct peaks of greater 

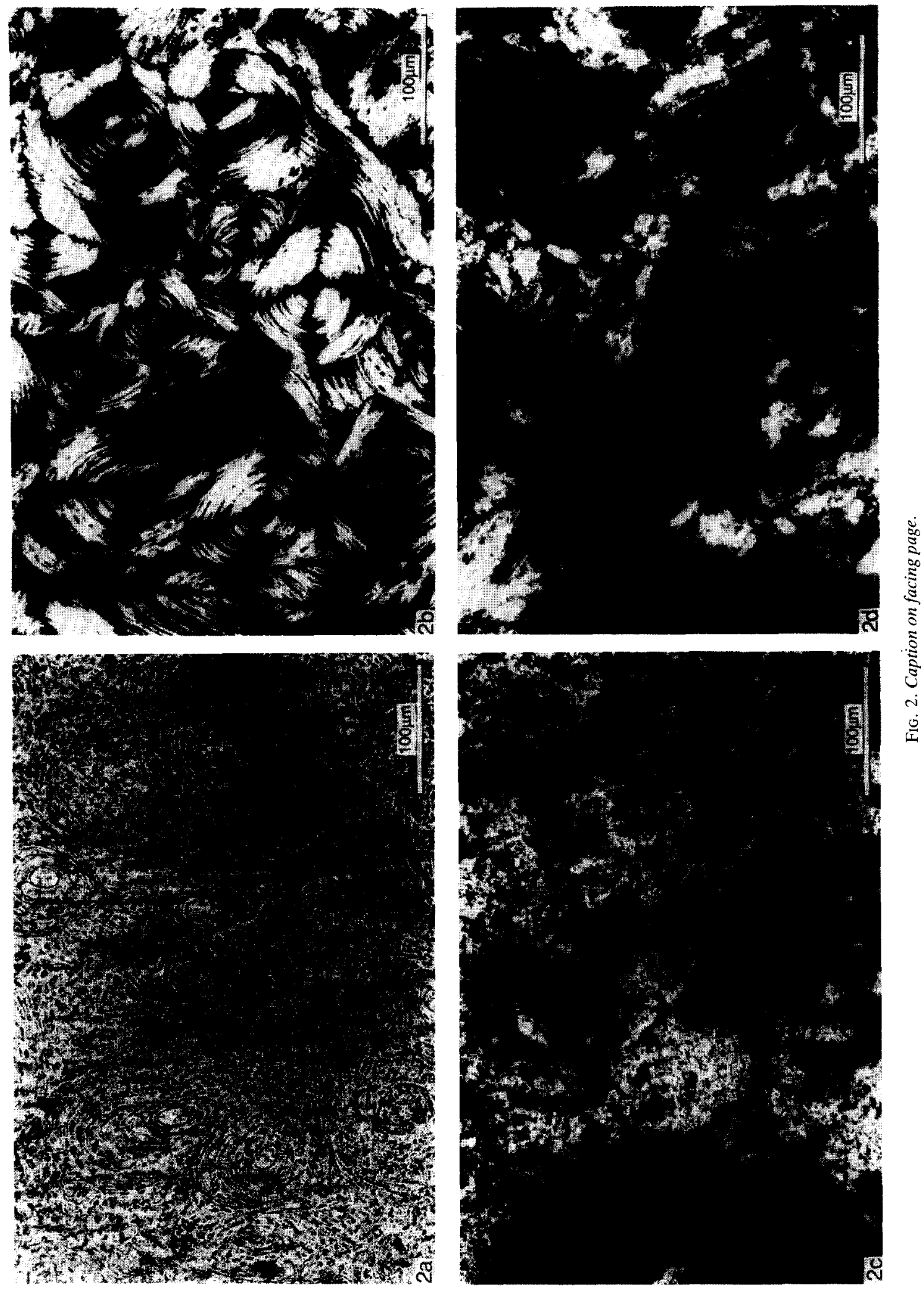
Table 1. Measures of bone preservation in an archaeological sample

\begin{tabular}{|c|c|c|c|c|}
\hline Sample & $\begin{array}{c}\text { Thin section } \\
(\% \text { intact structure })^{*}\end{array}$ & $\begin{array}{c}\text { X-ray } \\
\text { diffraction } t\end{array}$ & $\%$ "Gelatin" & ppm Sr \\
\hline 2839 & $30-40 \%$ & $20.1(27.0)$ & 12.2 & 220 \\
\hline 2835 & $25-30 \%$ & $20.5(25.8)$ & 10.8 & 283 \\
\hline 2931 & $7-10 \%$ & & 5.8 & 275 \\
\hline 2879 & $5-10 \%$ & & 5.5 & 213 \\
\hline 2032 & $5-10 \%$ & & 11.3 & 241 \\
\hline 2836 & $<5 \%$ & & 9.5 & 273 \\
\hline 2861 & trace & $18.9(35.0)$ & 8.2 & 164 \\
\hline 2865 & trace & $18.9(33.9)$ & 5.2 & 185 \\
\hline $3714($ modern $)$ & $\approx 100 \%$ & $22.3(21.8)$ & 25 (avg.) & NA $\ddagger$ \\
\hline
\end{tabular}

*This includes osteons, secondary osteons, lamellar bone.

$\rightarrow$ Initial value is cumulative width at half-peak-height of major peaks (cumulative peak height in parenthesis).

$\doteqdot$ Not applicable--modern sample from different geographic region.

intensity. The less altered samples were intermediate between these extremes. To supplement this qualitative assessment of the diffraction data, patterns showing the extremes of intensity were quantified using two different approaches. The commonly accepted method of measuring full width at half the maximum height of each peak was problematic because it was difficult to extrapolate the shoulders of superimposed peaks for measurement. Instead, we measured the width of the entire envelope at half height for each of the superimposed peaks.

The other approach was to sum the height of the major peaks for each of the samples. This method avoided the difficulties produced by the overlap of peaks which occurred in the better preserved samples. Further, this method emphasized ease of measurement; a distinct advantage because the purpose was elimination of samples inappropriate for composition analysis. As particle grain size was fine enough to ensure minimal differences due to preferred orientation between samples and because the diffractometer instrumentation settings were kept constant for all samples, the differences in peak intensities should be significant and reflect relative degrees of diagenetic alteration within the samples. In the modern samples it was difficult to measure the peaks due to the lack of definition of individual peaks. In these cases, the intensity at the $2 \theta$ angle where the peaks would occur was measured.

As can be seen in Table 1, the quantified data confirm the general impression gained by a visual examination of the profiles, and fit in neatly with the thin section results. The least well-preserved bone yielded the highest cumulative $X$-ray peak intensities and the lowest cumulative peak widths. The best preserved material had the lowest cumulative peak intensity and the highest cumulative peak widths.

\section{Discussion}

The results of both the X-ray diffractometry and estimation of retained histological structure suggest post-mortem alteration to varying extents. In order to assess the implications for trace element analysis some consideration of the nature of this alteration is necessary.

When viewed in thin section, the bone displayed areas of altered osteons which were filled with a pale green to tan substance as seen under plane light (Fig. $2 \mathrm{c})$. Viewing the same region under polarized light (Fig. 2d) suggests an apparent lack of crystallinity because no light is transmitted. The nature of this alteration material could not be ascertained using the polarizer, but, as discussed above, the diffraction data indicate that all of the samples are composed exclusively of hydroxyapatite. Within the range of $20^{\circ}-40^{\circ} 2 \theta$ (Fig. 3), which incorporated the seven peaks of greatest intensity, only one small peak near $29^{\circ} 2 \theta$ indicates any mineral phase other than apatite. This peak, which may be the carbonate affiliated with apatite (PoSNER, 1969), is of the same order of magnitude in the modern and archaeological samples. For this reason, it is not thought to be diagenetic in

FIG. 2. a. A tibia thin-section of a cadaver specimen in plane light. Note the histological detail in which Haversian systems are clearly observable. $b$. The same thin section as in a, in polarized light. The pattern of light and dark indicates the presence of crystallized bone mineral oriented by the organization of collagen fibrils. c. A tibia thin-section in plane light of an archaeological specimen (human) from the Georgia coast. Few complete Haversian systems remain in this section; the majority of the area exhibits no histological structure. $\mathrm{d}$. The same thin section as in $\mathrm{c}$ in polarized light. The surface appears to be poorly mineralized because no light is transmitted, as compared with $b$. As discussed more thoroughly in the text, this is most likely due to the loss of organization accompanying the loss of the organic component of the bone. 

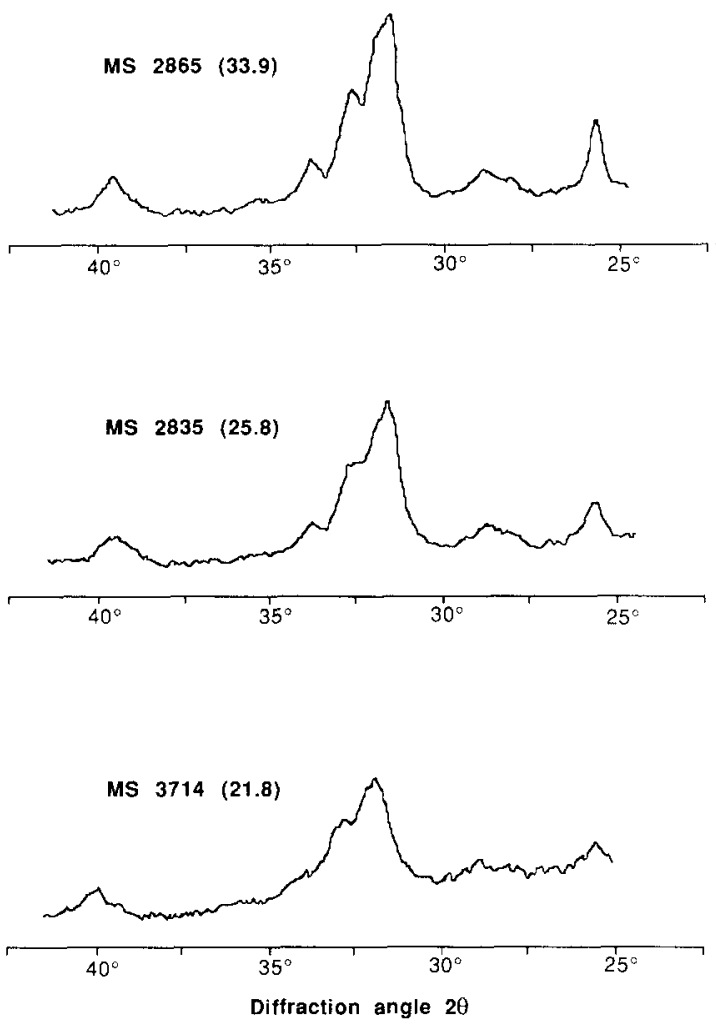

For al samples: $35 \mathrm{Kv}, 10 \mathrm{ma}, 1000 \mathrm{cps}, \mathrm{T} . \mathrm{C}=2.0$

Fig. 3. X-ray diffraction patterns of unheated, powdered human bone (source $\mathrm{Cu}, k \alpha$ ). The pattern at the bottom is that from the same cadaver specimen as shown in thin section in Fig. 2a and b. The blunted, diffuse peaks indicate a material with extremely small crystals. The other two patterns were made from archaeological bone from the coast of Georgia. The pattern at the top is the same specimen shown in thin section in Fig $2 \mathrm{c}$ and d. This pattern has more clearly defined peaks, indicating a more crystalline material than is present in the modern bone sample. The middle pattern is a sample from the Georgia coast which had more histological structure in the thin section than the other sample. The X-ray diffraction pattern is intermediate between the modern and the most degraded sample. The only mineral phase which is apparent in these three specimens is apatite.

origin. Thus, there remains the question of why the polarizer indicates lack of crystallinity, yet the X-ray diffraction profiles clearly indicate the ubiquitous presence of apatite.

The pattern produced in polarized light is a result both of the crystal and its orientation. The orientation of crystals in bone is determined by the organization of the collagen fibrils. In combination, the appearance of the thin section and the low yield of organic matter, as defined by \% "gelatin" (Table 1) in the archaeological samples, suggest that the lack of pattern under polarized light in these samples is due to the loss of the organic component, with resultant loss of orientation of the hydroxyapatite crystals. The $X$-ray diffraction patterns indicate that the archaeological samples are more crystalline or have larger crystals than the modern sample. These larger (or more perfect) crystals may be located within the areas without histological structure, yet are too small for the resolving power of the polarizer. Alternatively, they may be located in the areas which retain histological structure. In cither case the data suggest that the bone mineral has been subjected to some alteration. The apatite crystals in the areas without histological structure may be biological apatite without orientation or they may be small crystals of apatite formed post-mortem. The apatite crystals in the areas with histological structure may be biological apatite, but the crystals differ in size or crystallinity from that during life, either through accretion or recrystallization.

Also included in Table 1 are the results of an analysis for $\mathrm{Sr}$ concentration. The two samples with the least amount of preserved structure and with the most intense $\mathrm{X}$-ray patterns have the lowest bone $\mathrm{Sr}$ concentrations. In the absence of the thin section and $\mathrm{X}$-ray diffraction studies, one might try to propose dietary differences to explain these results even though all of these samples represent people who lived at the same time in the same geographic area with the same subsistence base (maize agriculture). Given these studies, however, it can be suggested strongly that the $\mathrm{Sr}$ concentrations (and presumably those of other trace elements as well) have been altered diagenetically and do not reflect a biological signature. An anonymous reviewer of this manuscript noted that the $d$ spacings of the X-ray diffraction patterns differ slightly between the bone from the best preserved and the least well preserved sample. This observation supports our proposal that diagenetic alteration of the chemical composition has occurred in the least well preserved samples. Even so, many, more careful, measurements with greater attention to instrumental precision are necessary to determine if this is indeed a real phenomenon.

\section{THE ORGANIC FRACTION OF BONE}

\section{Problem}

As discussed in other papers in this volume, $\sim 25 \%$ of the dry weight of bone is organic (Boskey and POSNER, 1984). This organic component consists largely of collagen, with $-10 \%$ of total organic $(<3 \%$ of bone dry weight) composed of non-collagenous proteins. When fresh bone powder is demineralized and hydrolyzed, a material (referred to as "gelatin" in this paper) is recovered in solution. In fresh bone, this "gelatin" is a mixture of collagen and non-collagenous proteins, with the vast majority being collagen. Previous studies have demonstrated that it has $\mathrm{C}$ and $\mathrm{N}$ stable isotope ratios that reflect those ratios in the diet of the organism (reviewed in Price et al., 1985).

In bone where the organic fraction has been re- 


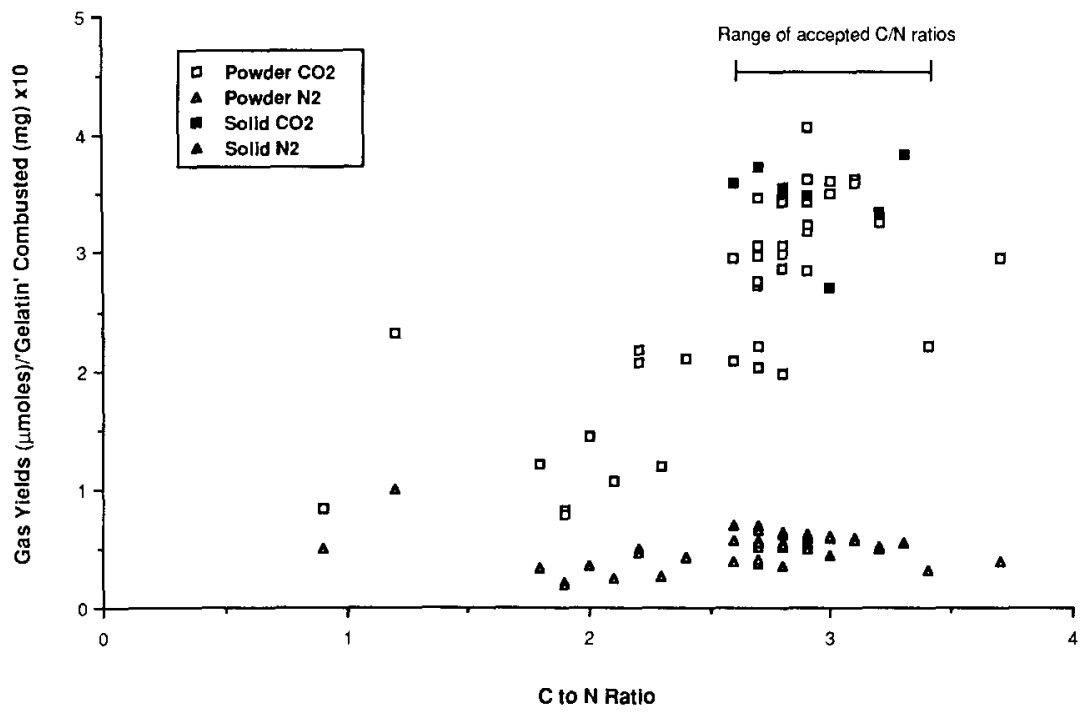

FIG. 4. The $\mu$ moles of $\mathrm{CO}_{2}$ and $\mathrm{N}_{2}$ produced per milligram of "gelatin" plotted against the $\mathrm{C}$ to $\mathrm{N}$ ratio of each sample. Although the volume of $\mathrm{N}_{2}$ per milligram of "gelatin" is relatively constant, the volume of $\mathrm{CO}_{2}$ is quite variable. Four "gelatin" samples extracted from bone powder with $\mathrm{C}$ to $\mathrm{N}$ ratios $<2.5$ and four with acceptable ratios were reprepared using pieces of the original bone rather than bone powder. These samples are shown as solid bone preparations in the figure. All have $\mathrm{C}$ to $\mathrm{N}$ ratios within the conventionally acceptable range of $2.6-3.4$.

duced experimentally through solubilization or burning to $<5 \%$ of its original dry weight, however, these isotopic ratios differ from those in fresh bone (Schoeninger and DeNiro, 1982) and no longer reflect diet isotopic ratios. In addition, the ratio of atomic $\mathrm{C}$ to atomic $\mathrm{N}$ of the "gelatin" recovered from these degraded samples differs from that in "gelatin" from fresh bone (normally 2.6-3.4) suggesting that the organic composition has been altered. One proposed explanation is that collagen may be lost preferentially in the degraded bone and, thus, the non-collagenous proteins make up a greater proportion of the "gelatin" recovered from degraded samples (Hare, 1980; Tuross, 1989). These non-collagenous proteins have $\mathrm{C}$ to $\mathrm{N}$ ratios which differ from that in collagen, although they appear to be identical to collagen in their isotopic ratios (MASTERS, 1987). Thus, it is unlikely that non-collagenous proteins are the source of the different isotopic ratios observed in degraded vs fresh bone. They may, however, account for the difference in $\mathrm{C}$ to $\mathrm{N}$ ratios. The common way of screening samples has been to reject any samples with $\mathrm{C}$ to $\mathrm{N}$ ratios outside the range of $2.6-3.4$ observed in "gelatin" from fresh, undegraded bone and with "gelatin" that is $<5 \%$ of the original dry weight. With the exception of the study by Tuross $e t$ al. (1988) the composition of the "gelatin" has not been determined.

In a recent project (MURRAY and Schoeninger, 1988 ) involving the analysis of human bone from an early Iron Age site (800-300 B.C.) in Yugoslavia, however, several samples had $\mathrm{C}$ to $\mathrm{N}$ ratios outside the acceptable range, but $>5 \%$ of the original dry weight was recovered as "gelatin". In fact, there was no relation between $\mathrm{C}$ to $\mathrm{N}$ ratios and percent "gelatin" recovered. A simple regression equation of $\mathrm{C}$ to $\mathrm{N}$ ratios vs "gelatin" yield had an $r^{2}$ value of 0.0005 . Further, yields of $\mathrm{CO}_{2}$ and $\mathrm{N}_{2}$ gases from this set of samples indicated that $\mathrm{CO}_{2}$ yields per milligram of "gelatin" varied widely across the total range of $\mathrm{C}$ to $\mathrm{N}$ ratios while the yield of $\mathrm{N}_{2}$ was relatively constant (Fig. 4). This contradicts our previous expectation that variation in $\mathrm{C}$ to $\mathrm{N}$ ratios would be due to variation in $\mathrm{N}$ through preferential loss relative to $\mathrm{C}$. It also brings into question the usefulness of the elemental ratio in conjunction with yield as an indicator of preservation. Some assessment of the composition of the "gelatin" appeared necessary.

\section{Sample preparation}

All of the samples in the original study had been prepared following the method of DENIRO and EPSTEIN (1981) as modified by SCHOENINGER and DENIRO (1984). Briefly, bone was ground at liquid $\mathrm{N}$ temperature to $<0.71 \mathrm{~mm}$, and demineralized by soaking in 1 $\mathrm{M} \mathrm{HCl}$ for $20 \mathrm{~min}$. After washing to neutrality with distilled water, the sample was placed in $0.125 \mathrm{M}$ $\mathrm{NaOH}$ for $20 \mathrm{~h}$ to remove humic acids. The sample was again washed to neutrality and the remaining organic material was hydrolyzed by placing it in 0.001 $\mathrm{M} \mathrm{HCl}$ at $90^{\circ} \mathrm{C}$ for $10 \mathrm{~h}$, and filtered. The "gelatin" in solution was freeze dried. Approximately $5 \mathrm{mg}$ of the "gelatin" was loaded into quartz tubes with elemental copper, cupric oxide wire, and silver as described previously (Schoeninger and DeNiro, 1984). The tubes were evacuated, sealed, and combusted at 
$800^{\circ} \mathrm{C}$ in a muffle furnace. The resulting $\mathrm{H}_{2} \mathrm{O}, \mathrm{CO}_{2}$ and $\mathrm{N}_{2}$ were separated cryogenically on a vacuum line $\left(\mathrm{N}_{2}\right.$ was collected on charcoal), measured manometrically, collected and sealed in Pyrex tubes. The isotope ratios were determined using mass spectrometry.

In order to assess whether the method of sample preparation could account for the unacceptable $C$ to $\mathrm{N}$ ratios, four samples with low ratios and four with acceptable ratios were reprepared using new aliquots of the original bone sample. Following the method of SEALY (1986), small chunks of bone $\left(\sim 0.5 \mathrm{~cm}^{2}\right)$ were placed in a $1 \%$ solution of $\mathrm{HCl}$ for about one week or until the sample became translucent. The sample was then placed in $0.125 \mathrm{M} \mathrm{NaOH}$ for removal of contaminating humic acids, rinsed to neutrality, freezedried, and then treated in the same manner as "gelatin" recovered from bone powder for production, collection, and analysis of the $\mathrm{CO}_{2}$ and $\mathrm{N}_{2}$. The bone samples reprepared by this method all had $\mathrm{C}$ to $\mathrm{N}$ ratios within the range normally found in fresh bone (also shown in Fig. 4). The material recovered from this process is also referred to as "gelatin" in this paper because it is the material loaded for combustion. The "gelatin" recovered from the demineralization of bone pieces differs from that recovered from bone powder in that the former is not the result of hydrolysis.

\section{Amino acid analysis}

In order to identify the composition of the "gelatin" which resulted from the two different preparations, the amino acid compositions of several samples and a collagen standard (NBS bovine collagen) were analyzed by a ninhydrin system. Following HARE (1977) the "gelatin" from each preparation of bone was hydrolyzed at $110^{\circ} \mathrm{F}$ for $20 \mathrm{~h}$ under a $\mathrm{N}$ atmosphere. An amino acid standard solution (Sigma No. AA-S-18) was analyzed at a concentration of 5 nmoles in $60 \lambda \mathrm{ddH}_{2} \mathrm{O}$. For each bone sample two "gelatin" extractions were analyzed (one powder preparation and one bone piece preparation). The "gelatin" samples and the collagen standard were analyzed at the same concentration as the amino acid standard. All of the "gelatin" samples which had C to $\mathrm{N}$ ratios within the range of 2.6-3.4 had profiles which compared favorably with the collagen standard. The "gelatin" samples with $\mathrm{C}$ to $\mathrm{N}$ ratios $<2.6$ did not have the same profile as the collagen standard.

An example of one set of these analyses is presented in Fig. 5 which is modified and redrawn from the original amino acid profiles. The figure displays the percent representation of each amino acid within the protein of the collagen standard and each "gelatin" sample (one from bone pieces and one from bone powder). The collagen standard shown at the top of the figure has a typical amino acid profile with approximately $30 \%$ glycine and a ratio of hydroxyproline to proline of $\sim 0.6$. These two measures are characteristic of collagen; no other protein has such a high glycine concentration and high hydroxyproline to proline ratio (BOSKEY and POSNER, 1984). The middle trace represents the "gelatin" made using bone pieces. It had an acceptable $\mathrm{C}$ to $\mathrm{N}$ ratio of 3.2. At the bottom is the trace from the "gelatin" made using bone powder. This "gelatin" had a $\mathrm{C}$ to $\mathrm{N}$ ratio of 1.9 which falls below the acceptable range. It should be emphasized that both of these are from the same bone sample and that this is not a unique occurrence, but is one that was repeated in all of the repreparations and duplications of the repreparations.

The "gelatin" prepared from bone pieces had an amino acid profile similar to that of the collagen standard. This suggests that the amino acid composition of this "gelatin" is very similar to collagen and that the bone, itself, is well enough preserved for isotopic analysis. In contrast, the amino acid profile of the "gelatin" prepared from bone powder of the same sample has an amino acid composition which differs from collagen. Although glycine is still at the highest concentration, it is somewhat low relative to the collagen standard. The hydroxyproline to proline ratio is high at 0.7 relative to the 0.6 ratio in the collagen standard and several amino acids present in collagen are not detectable in this "gelatin". The significance of this difference overall is unknown at this time, although the apparent enrichment of tyrosine is an artifact of a buffer change.

Of greater relevance for this study is the observation that the overall concentration of protein within the two sample preparations differs markedly. Because the collagen standard and "gelatins" were prepared at the same concentration for amino acid analysis, the intensity of the peak in the original amino acid plots (not shown here) is proportional to the concentration. The intensity of the highest peak (glycine) can be represented by the maximum voltage (in $\mathrm{mV}$ ). The maximum voltage of the glycine peak in each analysis is given in Fig. 5 and provides a rough estimate of the concentration of protein in each "gelatin". The collagen standard ran on the amino acid analyzer at $200 \mathrm{mV}$. Because it contains nearly $100 \%$ protein, $200 \mathrm{mV}$ represents $100 \%$ protein in this set of preparations. The "gelatin" from the sample prepared from bone pieces also ran at $200 \mathrm{mV}$ indicating that it is composed of nearly $100 \%$ protein. The voltage during the analysis of the "gelatin" prepared from bone powder was only $10 \mathrm{mV}$. When compared with that from the collagen standard it appears that this "gelatin" preparation contains $<10 \%$ protein. In other words, $>90 \%$ of the material extracted from the bone powder is non-collagenous and probably non-proteinaceous.

Further support is provided by a consideration of the $\mathrm{C}$ to $\mathrm{N}$ ratios. The $\mathrm{C}$ to $\mathrm{N}$ ratios of each amino acid (taken from Stryer, 1975) are listed below their respective peaks at the bottom of Fig. 5. For example, glycine has a $\mathrm{C}$ to $\mathrm{N}$ ratio of 2 ; there are two $\mathrm{C}$ atoms 

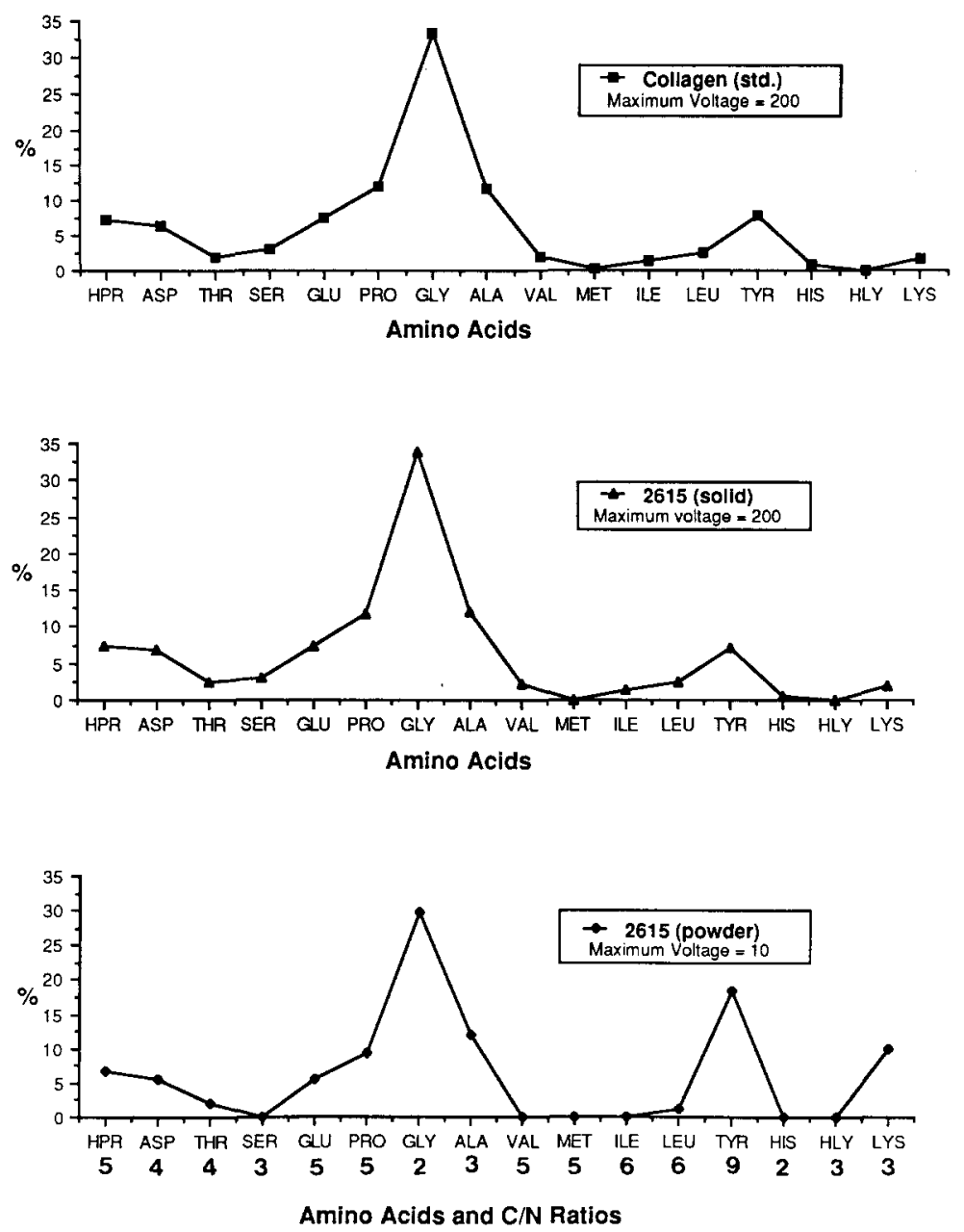

FIG. 5. Plot of \% representation of individual amino acids in the protein component of three "gelatin" samples. The graph at the top represents a collagen standard. The middle graph represents "gelatin" from small pieces of bone demineralized in $1 \% \mathrm{HCl}$. The graph at the bottom represents "gelatin" extracted from bone powder prepared according to DENIRo and EPSTEIN (1981). The "gelatin" from the solid bone preparation has an amino acid profile similar to collagen, whereas the "gelatin" from the powder preparation of the same bone sample does not. These graphs were redrawn from the original profiles produced by a ninhydrin amino acid analyzer. The intensity of the peaks. in the original profiles is proportional to the voltage; the concentration of protein in each "gelatin" is proportional to overall intensity. Thus, the voltage is an indication of protein concentration because all three were prepared at the same concentration. The collagen standard (representing $100 \%$ protein) ran at $200 \mathrm{mV}$ as did the preparation from bone pieces. The "gelatin" from the bone powder preparation ran at $10 \mathrm{mV}$ indicating that $<10 \%$ of the "gelatin" is protein. The numbers across the bottom of the graph are the $\mathrm{C}$ to $\mathrm{N}$ ratios of each amino acid. A "predicted" $\mathrm{C}$ to $\mathrm{N}$ value for the protein as a whole is calculated by multiplying the $\%$ representation of the amino acid by its $\mathrm{C}$ to $\mathrm{N}$ ratio. The predicted value for all three proteins are presented in Table 2.

and one $\mathrm{N}$ atom in each molecule of glycine. Glycine is unusual in this respect because most amino acids have much higher $\mathrm{C}$ to $\mathrm{N}$ ratios, usually closer to 5 or 6. Multiplying each amino acid $\mathrm{C}$ to $\mathrm{N}$ ratio by its percent representation in collagen (e.g. $30 \%$ glycine $\times 2$ ) and adding all of the values together produces a predicted (expected) $\mathrm{C}$ to $\mathrm{N}$ ratio for collagen. The predicted ratio in each "gelatin" can be calculated in the same way. When this is done, the solid bone preparation of the "gelatin" in Fig. 5 has a predicted ratio of 3.9; the same ratio predicted for the collagen standard. This reflects the fact that its composition is virtually identical to the collagen standard. The bone powder preparation, on the other hand, has a predicted $\mathrm{C}$ to $\mathrm{N}$ ratio of 4.3 reflecting the non-collagenous amino acid composition of its protein component.

The $\mathrm{C}$ to $\mathrm{N}$ ratios, measured (referred to as "observed" in Table 2) for each "gelatin" sample and the collagen standard were then compared with the predicted value. The volumes of $\mathrm{CO}_{2}$ and $\mathrm{N}_{2}$ produced during combustion of the collagen standard and the two "gelatin" preparations were measured manometrically on a vacuum line as described in greater detail above. The volumes were then transposed to an 
Table 2. $\mathrm{C}$ to $\mathrm{N}$ ratios based on amino acid composition

\begin{tabular}{lccc}
\hline & $\begin{array}{c}\% \\
\text { Protein }\end{array}$ & $\begin{array}{c}\text { Predicted } \\
\mathrm{C} / \mathrm{N}\end{array}$ & $\begin{array}{c}\text { Observed } \\
\mathrm{C} / \mathrm{N}\end{array}$ \\
\hline Collagen standard & 100 & 3.9 & 3.1 \\
2615 solid bone & 80 & 3.9 & 3.2 \\
2615 bone powder & 10 & 4.3 & 1.9 \\
\hline
\end{tabular}

atomic ratio. Other samples not used in this study were analyzed on a $\mathrm{CHN}$ analyzer in order to check atomic ratios calculated from manometrically determined volumes. The two compared extremely favorably (GRUPE, pers. comm.), thus, the manometrically measured volumes can be accepted as providing accurate $\mathrm{C}$ to $\mathrm{N}$ ratios.

In all cases, the predicted $\mathrm{C}$ to $\mathrm{N}$ ratio is higher than the observed; in fact, the predicted value is higher than the commonly accepted range for these ratios (3.9 vs 2.6-3.4). At this time, we have no explanation for this observation. The difference between predicted and observed in the powder preparations, however, was significantly larger than was true for the collagen standard or for the solid bone preparation.

As mentioned previously, $90 \%$ of the "gelatin" from the bone powder preparation consists of a noncollagenous substance. Because the "gelatin" as a whole had a $\mathrm{C}$ to $\mathrm{N}$ ratio of 1.9 , the non-collagenous substance must have a $\mathrm{C}$ to $\mathrm{N}$ ratio close to 1 . This is necessary to balance out the $4.3 \mathrm{C}$ to $\mathrm{N}$ ratio predicted from the amino acid composition of the protein portion ( $<10 \%$ of the "gelatin"). No amino acids have such large amounts of $\mathrm{N}$ relative to $\mathrm{C}$. The amino acid which most closely approaches 1 is glycine (ratio of 2). Yet the profiles indicate that there is not enough glycine in the "gelatin" to produce a $\mathrm{C}$ to $\mathrm{N}$ ratio of
1.9. MASTERS (1987) suggested contamination by ammonia, yet, there was no observable ammonia peak in any of the amino acid profiles from the samples in the present study. Two organic substances (polyamines and nucleic acids) have $\mathrm{C}$ to $\mathrm{N}$ ratios close to 1 . Both of these are found in bacteria, and, thus, are possible contaminants of buried bone. Inorganic $\mathrm{N}$ (such as from soil nitrates) or urea are also possibilities, but it seems unreasonable that these would be recovered preferentially in the powdered bone preparation and not in the solid bone preparations. At this time, the identification of the substance extracted in the powder preparation is not known.

\section{Discussion}

These results suggest that the method of preparing bone using small chunks rather than powder has a greater chance of producing "gelatin" that has biological integrity. One potential problem with the solid bone preparation, however, is a tendency to remove the sample from the acid before it is completely demineralized. Figure 6 presents human bone samples from the late prehistoric period in South Dakota some of which have not been completely demineralized. These samples have yields (defined as weight of extracted "gelatin" per dry bone weight) of $>25 \%$. Even so, these samples have $\mathrm{C}$ to $\mathrm{N}$ ratios within the conventionally accepted range of values and would mistakenly be chosen for analysis if only the $\mathrm{C}$ to $\mathrm{N}$ ratios were used for selection.

Thus, neither the superficial appearance, the percentage of residue extracted, nor the $\mathrm{C}$ to $\mathrm{N}$ ratios can be used to predict how well collagen is preserved. By

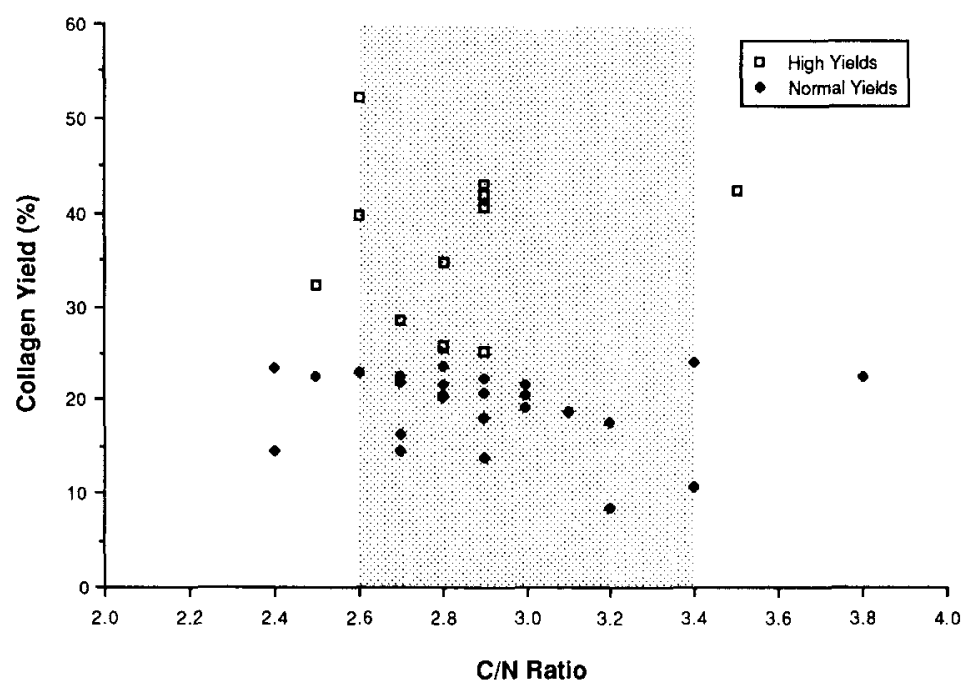

The shaded area represents our range of conventionally accepted $\mathrm{C} / \mathrm{N}$ ratios

FIG. 6. Plot of percent of original bone dry weight recovered after demineralization in $1 \% \mathrm{HCL}$ vs $\mathrm{C}$ to $\mathrm{N}$ ratios. Incompletely demineralized samples (indicated by having percent recovery $>25 \%$ ), still have $\mathrm{C}$ to $\mathrm{N}$ ratios within the conventionally accepted range. 
analyzing the amino acid composition the preservation can be assessed, although this method is too time consuming to be used on every sample. In a less negative vein, however, it appears that using a solid bone preparation produces "good gelatin" (if such is retained in the bone), as long as demineralization is complete. Our analysis of the protein content in a number of samples suggests that although we can not model accurately the diagenesis of bone collagen at this time, we can produce samples for isotopic analysis which retain a biological signature.

\section{CONCLUSIONS}

Bone is a complex tissue with individual components subject to degradation and/or replacement by physical and biological processes during burial. The preservation of the inorganic and organic fractions of bone must be assessed separately, because different depositional environments can produce samples in which one of the components is unacceptably altered, while the other is sufficiently preserved to yield dietary information. It would not be practical for the techniques mentioned here to be applied to every specimen in a sample set, but trials must be made to diagnose the general condition and the variability of preservation in the sample.

Based on the studies presented above, it is possible to eliminate samples for analysis of trace elements in the inorganic fraction of bone when a thin section of the bone reveals a lack of histological structure. The $\mathrm{X}$-ray diffraction profiles, in conjunction with the thin section appearance, provide information about the nature of the diagenetic process. Even so, for routine scanning of samples considered for analysis it is unnecessary to analyze powder samples by X-ray diffractometry.

For the analysis of the organic fraction for stable isotope ratios, "gelatin" retaining a biological signature is most likely to be recovered by using a whole bone acid preparation. Except with extremely wellpreserved samples ("gelatin" $>15 \%$ dry wt) use of C to $\mathrm{N}$ ratios and "gelatin" as percent of dry weight are extremely unreliable indicators of the integrity of collagen. Regrettably, systems for producing amino acid profiles are not easily available to many researchers. Yet, in cases of sample sets which have consistently low yields $(<10 \%)$ it is prudent to have a subset of the samples analyzed for amino acid composition.

Even though we can isolate altered specimens and sample sets, we cannot always identify the diagenetic process or agent involved. Diagenesis of bone in archaeological and fossil sites will certainly turn out to be a complex interaction of several factors, due to diverse depositional settings and periods of burial. Understanding these processes should provide more meaningful and powerful predictive tools for sampl- ing skeletal remains for chemical and isotopic analysis.

Acknowledgements-We wish to thank several people whose varied expertise made this study possible. Drs Noreen Tuross of the Carnegie Institute (Washington, DC) and Sam Stout of the University of Missouri generously provided guidance in the amino acid analysis and in the preparation of the bone thin sections, respectively. Ms Akiko Ushida assisted with the preparation and analysis of the thin sections and X-ray diffraction samples. Dr John Merkel of Harvard University helped in the X-ray diffractometry, Dr Donald Pate provided the cadaver specimen, and Ms Reneé Robinson did some of the mass spectrometry. We appreciate discussions with Drs Brian Burke of Harvard Medical School and Noreen Tuross about the nature of the degraded "gelatin". Dr James Burton of the University of Wisconsin (Madison) and an anonymous reviewer read a previous draft thoroughly and made very useful suggestions. We appreciate their time expended in this effort. This work was funded by grants from the Faculty of Arts and Sciences, Harvard University.

\section{REFERENCES}

Boskey A. L. and Posner A. S. (1984) Structure and formation of bone mineral. In Natural and Living Biomaterials (eds G. W. Hastings and P. DucheYNe) pp. 28 41. CRC Press.

DeNiro M. J. and EPSTEIN S. (1981) Influence of diet on the distribution of nitrogen isotopes in animals. Geochim. cosmochim. Acta 45, 341-351.

GruPE G. (1988) Impact of the choice of bone samples on trace element data in excavated human skeletons. J. arch. Sci. 15, 123-129.

Grupe G. and Herrmann B. (1988) Trace Elements in Environmental History. Springer.

Grupe G. and Piepenbrink H. (1989) Impact of microbial activity on trace element concentrations in excavated bones. Appl. Geochem. 4, 293-298.

HANSON D. and Buikstra J. E. (1987) Histomorphological alteration in buried human bone from the Lower Illinois Valley: implications for palaeodietary research. $J$. archaeol. Sci. 14, 549-563.

HARE P. E. (1977) Subnanomole-range analysis. Methods in Enzymology (ed. C. H. W. Hirs) pp. 3-18. University of Chicago Press.

HARE P. E. (1980) Organic geochemistry of bone and its relation to the survival of bone in the natural environment. In Fossils in the Making (ed. A. K. BEHRENSMEYER and A. P. Hill) pp. 208-222. University of Chicago Press.

LAmbert J. B., Simpson S. V., Szpunar C. B. and Buikstra J. E. (1984) Ancient human diet from inorganic analysis of bone. Accounts chem. Res. 17, 298-305.

MAsters P. M. (1987) Preferential preservation of noncollagenous proteins during bone diagenesis: implications for chronometric and stable isotopic measurements. Geochim. cosmochim. Acta 51, 3209-3214.

Murray M. D. and Schoeninger M. J. (1988) Diet, status, and complex social structure in Iron Age central Europe: some contributions from bone chemistry. In Tribe and Polity in Late Prehistoric Europe (eds D. B. GIBSon and M. D. Geselowitz) pp. 155-178. Plenum.

Pate F. D., Hutton J. T. and Norrish K. (1989) Ionic exchange between soil solution and bone: toward a predictive model. Appl. Geochem. 4, 303-316.

Posner A. S. (1969) Crystal chemistry of bone mineral. Physiol. Rev. 49, 760-792.

Price T. D., Schoeninger M. J. and Armelagos G. J. (1985) Bone chemistry and past human behavior: an overview. J. Human Evol. 14, 419-447. 
Schoeninger M. J. (1979) Diet and status at Chalcatzingo: some empirical and technical aspects of strontium analysis. Am. J. phys. Anthropol. 51, 295-310.

Schoeninger M. J. and DeNiro M. J. (1982) Diagenetic effects on stable isotope ratios in bone apatite and collagen. Abst. Am. J. phys. Anthropol. 57, 225.

Schoeninger M. J. and DeNiro M. J. (1984) Nitrogen and carbon isotopic composition of bone collagen from marine and terrestrial animals. Geochim. cosmochim. Acta 48, 625-639.

Schoeninger M. J., van der Merwe N. J., Moore K. M., LEe ThORP J. and LARSEN C. (1989) Decrease in diet quality between the prehistoric and the contact period on St. Catherines Island, Georgia. American Museum of Natural History Press. Volume editor, C. LARSEN, in press.

SEALy, J. C. (1986) Stable Carbon Isotopes and Prehistoric
Diets in the South-western Cape Province, South Africa. Cambridge Monographs in African Prehistory.

Shipman P., Foster G. and Schoeninger M. J. (1984) Burnt bones and teeth: an experimental study of colour, morphology and shrinkage. J. archael. Sci. 11, 307-325.

StrYer A. (1975) Biochemistry. W. H. Freeman.

STout S. (1978) Histological structure and its preservation in ancient bone. Current Anthropol. 19, 601-604.

Tuross N. (1989) Albumin preservation in the Taima-taima mastodon skeleton. Appl. Geochem. 4, 255-259.

Tuross N., Fogel M. L. and Hare P. E. (1988) Variability in the preservation of the isotopic composition of collagen from fossil bone. Geochim. cosmochim. Acta 52, 929_ 935.

Walker A., Zimmerman M. R. and Leakey R. E. F. (1982) A possible case of hypervitaminosis $\mathrm{A}$ in Homo erectus. Nature 296, 248-250. 